\title{
Microclima e a arborização: o caso de duas áreas do Núcleo Marabá Pioneira, Marabá - Pará ${ }^{1}$
}

\author{
Antônio Pereira Júnior²; Edmir dos Santos Jesus ${ }^{3}$; Milka Beatriz Faval Bastos ${ }^{4}$; Rafael Victor Castro \\ Santos ${ }^{5}$
}

Resumo: Estudos a respeito do clima urbano, envolvem inúmeras variáveis climáticas, tais como, temperatura, umidade do ar e vegetação. A pesquisa objetivou determinar a tendência de duas variáveis meteorológicas (temperatura do ar umidade relativa), em relação a arborização, sensação e percepção térmica higrométrica da população no microclima de duas áreas (A1 = Avenida Antônio Maia; A2 = Rua 5 de abril) do Núcleo Marabá Pioneira. Para a mensuração de temperatura e umidade do ar, aplicou-se a metodologia preconizada pelo Instituto Agronômico de Campinas (IAC), adaptada para os horários e números de coleta. Para obtenção de dados acerca do conforto térmico, aplicaram-se setenta formulários mistos durante dois dias seguidos nas 12 horas. A sensação térmica foi classificada de acordo com o contido no Predicted Mean Vote (PMV) e o desconforto, com o Índice de Desconforto de Thom (ID). Foram realizadas 12 leituras diárias (às 06h e às 17h) termo higrométricas a cada uma hora, nos quatro abrigos meteorológicos (dois em cada área), durante 23 dias do mês de julho de 2015. Os resultados indicaram que a temperatura do ar apresenta tendências a elevação, e a umidade relativa do ar, apresenta tendência oposta. A sensação térmica é de muito calor (+3), a satisfação quanto ao sombreamento, foi classificada como boa $(\mathrm{A} 2=50 \%)$ e regular $(\mathrm{A} 1=41,67 \%)$, o conforto térmico $\left(\mathrm{A} 1=28,76^{\circ} \mathrm{C} ; \mathrm{A} 2=27,70{ }^{\circ} \mathrm{C}\right)$, oscila entre desconfortável a muito desconfortável. Logo, há necessidade de melhorar a arborização no Núcleo Marabá Pioneira, para diminuir o índice de desconforto e melhorar a qualidade de vida da população.

Palavras - chave: Vegetação; Umidade relativa; Temperatura do ar.

\section{Microclimate and tree canopy cover: The case of two areas in Núcleo Maraba Pioneira - Pará.}

\begin{abstract}
Studies of the urban climate involve numerous climatic variables, such as temperature, air humidity and vegetation. The objective of this research was to determine the trend of two meteorological variables (air temperature relative humidity), in relation to the arborization, sensation and thermal hygrometric perception of the population in the microclimate of two areas (A1 = Avenue Antônio Maia; A2 = Street 5 de Abril) Core Marabá Pioneira. For the measurement of temperature and humidity of the air, the methodology recommended by the Agronomic Institute of Campinas (IAC), adapted for the schedules and collection numbers, was applied. To obtain data on thermal comfort, seventy mixed forms were applied for two consecutive days at 12 hours. The thermal sensation was classified per the contained in the Predicted Mean Vote (PMV) and the discomfort, with the Thom Discomfort Index (ID). Twelve daily readings (6:00 a.m. to 5:00 p.m.) were carried out at each hour in the four meteorological shelters (two in each area) during 23 days of July 2015. The results indicated that the air temperature has tendencies to elevation, The relative humidity of the air, presents opposite tendency. The thermal sensation is very hot $(+3)$, the satisfaction with shading was classified as good $(\mathrm{A} 2=50 \%)$ and regular $(\mathrm{A} 1=41.67 \%)$, thermal comfort $\left(\mathrm{A} 1=28.76^{\circ} \mathrm{C} ; \mathrm{A} 2=27.70^{\circ} \mathrm{C}\right)$, ranges from uncomfortable to very uncomfortable. Therefore, there is a need to improve afforestation in the Marabá Pioneira Nucleus, in order to reduce the discomfort index and the quality of life of the population.
\end{abstract}

Keywords: Vegetation; Relative humidity; Air temperature.

\footnotetext{
${ }^{1}$ Recebido em 08.01.2016 e aceito para publicação como artigo científico em 05.12.2016.

${ }^{2}$ Biólogo, M.Sc., Universidade do Estado do Pará. E-mail: <jrecobio@ yahoo.com.br>.

${ }^{3}$ Meteorologista, Dr., Universidade do Estado do Pará. E-mail: 〈edmir.jesus@ gmail.com>.

${ }^{4}$ Acadêmica, Engenharia Ambiental, Universidade do Estado do Pará. E-mail: 〈bfaval2@gmail.com>.

${ }^{5}$ Acadêmico, Engenharia Ambiental, Universidade do Estado do Pará. E-mail: <eng.rvcs@ gmail.com>.
} 


\section{Introdução}

O clima é o efeito ativo de fatores globais (latitude, altitude), locais (revestimento do solo e topografia) e elementos de meteorologia (temperatura, umidade), que dão feição à localidade. $\mathrm{O}$ conceito de clima refere-se tanto a vastas regiões do planeta quanto a uma cidade, estado, país. Além disso, para caracterização do clima de uma região, são consideradas variáveis ambientais, como a média térmica. Por isso, o clima é definido como a inter-relação de um conjunto de condições atmosféricas típicas de um dado lugar (BARBIRATO et al., 2007; MENDONÇA e DANNI-OLIVEIRA, 2007; RORIZ, 2008).

Quanto ao conceito de microclima, ele é definido como resultado das variações climáticas decorrentes de um espaço de proporções reduzidas, em que os principais elementos climáticos (temperatura e umidade do ar, radiação e velocidade do vento) sofrem influência direta do seu entorno: elemento geográfico (topografia), edificações (gabarito, ocupação), malha urbana, revestimento, vegetação. Horizontalmente, ele ocorre em apenas alguns metros do nível do solo, $2 \mathrm{~m}$ acima e $1 \mathrm{~m}$ dentro do solo (PILLAR, 2007), até $10 \mathrm{~km}$; verticalmente, abaixo de $100 \mathrm{~m}$; na escala temporal, varia de alguns minutos a dia, e ocorre em ruas, edificações /casas (BORGES, 2009).

Ademais, os elementos climáticos interferem diretamente na sensação térmica dos pedestres, alteram a percepção, a preferência e a satisfação térmica das pessoas. Em relação a sensação térmica, ela é um dos fatores mais importantes na decisão de permanência em um ambiente ao ar livre. Um exemplo clássico da problemática das cidades é a dificuldade de se obter sensações térmicas agradáveis, o que tem levado a população a recorrer às formas artificiais de aquecimento/resfriamento (...) em cidades com diferentes configurações climáticas (SOUZA, 2013).

Outra atuação direta desses elementos climáticos, é sobre o conforto térmico ambiental em áreas abertas. Esse tipo de conforto é definido como um conjunto de condições em que os mecanismos de autorregulação são mínimos, ou ainda na zona delimitada por características térmicas em que o maior número de pessoas manifeste se sentir bem. Isso porque os aspectos microclimatológicos na interação higrotérmica entre indivíduo e meio ambiente se referem às condicionantes do ambiente (GOMES, 2007; MONTEIRO, 2008).

Uma dessas condicionantes é a vegetação que exerce um papel fundamental na (...) melhoria do conforto térmico humano em ambientes abertos. Suas principais contribuições no microclima estão relacionadas aos benefícios do sombreamento direto e da moderação do calor solar através da evapotranspiração, convertendo radiação solar incidente em calor latente que não contribui para o aquecimento (MCPHERSON, 1994; VARGAS et al., 2008). Em outras palavras, os espaços públicos externos compostos em seu desenho por ambientes arborizados garantem uma boa qualidade a estes espaços. Quando esse espaço for constituído por áreas verdes, o mesmo desempenha um importante papel ambiental, uma vez que possui o efeito de amenizar o clima (OLIVEIRA, 2011).

Decerto, as árvores podem alterar a incidência da radiação consideravelmente e, em maior quantidade proporcionam grande alívio, devido ao sombreamento gerado, nos períodos mais quentes. Além do sombreamento, e de atenuar a radiação solar incidente, a arborização auxilia na umidificação do ar (KÁNTOR et al., 2008; MASCARÓ L e MASCARÓ J., 2009). Por isso, a arborização é de extrema importância para o conforto do ser humano, pois ela diminui a temperatura em $3{ }^{\circ} \mathrm{C}$ a $4{ }^{\circ} \mathrm{C}$, e aumenta a umidade relativa em $3 \%$ a $10 \%$. Dependendo do tipo de cobertura vegetal, esta pode absorver até $50 \%$ de radiação de onda curta, e até $95 \%$ de radiação de onda longa (BARBIRATO et al., 2007; GONÇALVES, 2009).

Indubitavelmente, as árvores e vegetações refrescam sua circunvizinhança de duas maneiras: (1) a evapotranspiração converte a energia solar em água evaporada ao invés de calor, mantendo as temperaturas da vegetação e 
do ar mais baixas; (2) árvores e vegetação promovem sombras para as superfícies e protegem-nas do calor do sol, mantendo essas superfícies mais frescas e reduzem o calor armazenado por elas (GARTLAND, 2010).

Em função disso, a arborização urbana deve ser trabalhada em esfera municipal. $\mathrm{O}$ planejamento e a gestão das áreas verdes, devem estar previstos no Plano Diretor e definidos segundo critérios de desenvolvimento e expansão urbana. Porém, este termo se refere ao espaço onde há o predomínio de vegetação, engloba: praças, bosques, canteiros centrais, avenidas e rotatórias de vias públicas. Porém, muitos destes locais sequer possuem vegetação, e isso é uma das maiores dificuldades de se considerar a arborização no planejamento das cidades (LONDE e MENDES, 2014).

Ademais, o processo de urbanização, que é conduzido pelo homem, é o principal agente modificador do ambiente, essas transformações na superfície tornam o clima, uma das variáveis mais importantes do meio natural, mais vulnerável, ocasionando sérios impactos. Dessa forma, as características climáticas da cidade são alteradas em micro e meso escalas, de modo geral elevando o calor e a precipitação pluviométrica, bem como alterando o fluxo de ventos e a umidade relativa do ar. Isso altera a qualidade do meio ambiente interferindo na qualidade de vida urbana que está diretamente ligada a diversos fatores, como a infraestrutura, o desenvolvimento econômico-social e a questão ambiental. Neste caso, as áreas verdes públicas possuem componentes essenciais para o bemestar da população, em cuja saúde física e mental interferem diretamente (LOBODA e DE ANGELIS, 2005)

Logo, estudar a relação entre arborização e microclima urbano é extremamente relevante porque ambos interferem no cotidiano das comunidades locais. Por tudo isso, o objetivo dessa pesquisa correlacional, foi determinar as tendências das variáveis meteorológicas (temperatura e umidade do ar) em duas áreas arborizadas no Núcleo Marabá Pioneira e sua influência sobre a percepção térmica higrométrica da população.

\section{Material e métodos}

Áreas da pesquisa

A pesquisa foi desenvolvida em duas áreas (A1 e A2) do Núcleo Marabá Pioneira (Tabela 01) (Figura 01A), e distam entre si, em 138,82 $\mathrm{m}$, em linha reta. Em cada uma das áreas, foram posicionados dois abrigos meteorológicos, contendo um termo higrômetro. Foram realizadas doze leituras diárias, no período de 01 a 31 de julho de 2015, de segunda a sexta-feira, das $06 \mathrm{~h}$ às $17 \mathrm{~h}$, durante vinte e três dias, o que totalizou um mil cento e quatro mensurações. Vale ressaltar que nessa pesquisa, não foram analisados variáveis incidentes sobre temperatura e umidade relativa do ar como: unidades arquitetônicas, tipos de pavimentações, tipos de vegetação, área do dossel, desempenho termo luminoso arbóreo, peculiaridades climáticas da região, etc.

O ponto A1, Avenida Antônio Maia, é delimitada, nas laterais direita e esquerda, pela Travessa Santa Terezinha e pela Avenida Getúlio Vargas respectivamente. Esta é parcialmente arborizada, com vegetação localizada apenas em um canteiro central e constituída exclusivamente por oitis (Licania tomentosa). As calçadas apresentam revestimento cimentício, e vias de fluxo, o revestimento é asfáltico. Nessa Avenida, o tráfego ocorre em fluxo (Oeste - Leste) e contra fluxo (Leste-Oeste) (Figura 01B).

A A2, corresponde à parte da Praça Duque de Caxias, rua 5 de Abril, com presença de mangueiras (Mangifera ssp), oitis (Licania tomentosa), canteiros com herbáceas, calçada com revestimento cimentício, e pavimentação da via de contra fluxo (sentido oeste-leste), asfáltica (Figura 01C).

As áreas são densamente edificadas e pavimentadas, contudo, se diferem quanto a densidade arbórea e unidades arquitetônicas que são: mistas (residencial e comercial) e específicas (residencial/comercial).

Instrumentos utilizados

Foram utilizados quatro abrigos 
meteorológicos, construídos de madeira prensada de $10 \mathrm{~mm}$ com 1,60 $\mathrm{m}$ de altura, pois, nesta altura, ocorre a temperatura representativa das condições experimentadas pelos seres humanos que vivem à superfície do globo terrestre (CRUZ, 2009). A parte superior desses abrigos mede $40 \mathrm{~cm}$ por $40 \mathrm{~cm}$ (Figura 02A). Nas partes frontais, laterais, superior e traseira foram feitos furos com broca de $1 / 2$ " para circulação do ar, evitando o calor excedente interno, esse procedimento tem a finalidade de não provocar variações na leitura das temperaturas. As duas áreas objetos dessa pesquisa foram monitoradas quanto à temperatura e a umidade relativa do ar, com o uso de termo higrômetros analógicos (modelo Inconterm 5195). Cada instrumento é constituído por dois termômetros simples, um com bulbo seco e outro com bulbo envolto em gaze sempre umedecida, que perde água a uma taxa dependente da concentração de vapor no ar), estes são alojados nos abrigos meteorológicos, fixados na parte superior com uma tachinha metálica e liga elástica de borracha fixada em um gancho metálico de $1 / 2$ " no assoalho interno (Figura 02B).

Tabela 01 - Localização das áreas de estudo. Núcleo Marabá Pioneira. Marabá - PA.

Table 01 - Location of the study areas. Núcleo Marabá Pioneira. Marabá - PA.

\begin{tabular}{|c|c|c|c|c|c|}
\hline Área & Local & Ponto & $\begin{array}{c}\text { Distância entre os } \\
\text { pontos (m) }\end{array}$ & $\mathbf{S}$ & $\mathbf{W}$ \\
\hline \multirow{2}{*}{ A1 } & Av. Antônio Maia c/ Trav. Santa Terezinha & 1 & \multirow{2}{*}{$\mathrm{P} 1 \rightarrow \mathrm{P} 2=102$} & $05^{\circ} 20^{\prime} 59,6^{\prime \prime}$ & $49^{\circ} 08^{\prime} 2,4^{\prime \prime}$ \\
\hline & Av. Antônio Maia c/Av. Getúlio Vargas & 2 & & $05^{\circ} 21^{\prime} 00.2^{\prime \prime}$ & $49^{\circ} 08^{\prime} 5.7^{\prime \prime}$ \\
\hline \multirow{2}{*}{ A2 } & Praça Duque de Caxias & 3 & \multirow{2}{*}{$\mathrm{P} 3 \rightarrow \mathrm{P} 4=72$} & $05^{\circ} 20^{\prime} 57.5^{\prime \prime}$ & $49^{\circ} 08^{\prime} 07.5^{\prime \prime}$ \\
\hline & Praça Duque de Caxias & 4 & & $05^{\circ} 20^{\prime} 58.5^{\prime \prime}$ & 4908'09.9'. \\
\hline
\end{tabular}

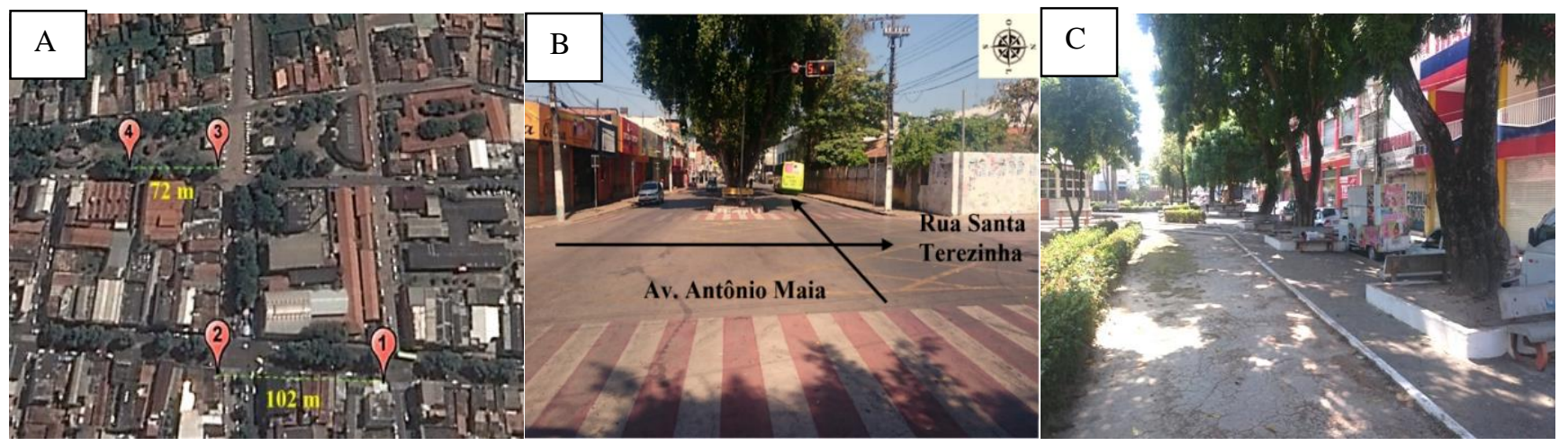

Figura 01 - A) Distância entre os pontos coleta. Núcleo Marabá Pioneira. Marabá - PA; B) A1 - Avenida Antônio Maia esquina com Rua Santa Terezinha. Núcleo Marabá Pioneira. Marabá - PA; C) A2 - Rua 5 de Abril. Praça Duque de Caxias. Núcleo Marabá Pioneira. Marabá - PA.

Figure 01 - A) Distance between the collection points. Núcleo Marabá Pioneira. Marabá - PA; B) A1 - Avenue Antonio Maia corner with Santa Terezinha Street. Núcleo Marabá Pioneira. Marabá - PA; C) A2 - Street April 5. Square Duque de Caxias. Núcleo Marabá Pioneira. Marabá - PA.

Fonte: A) Adaptado do Google Earth (2015); B) e C) Autores (2015). 

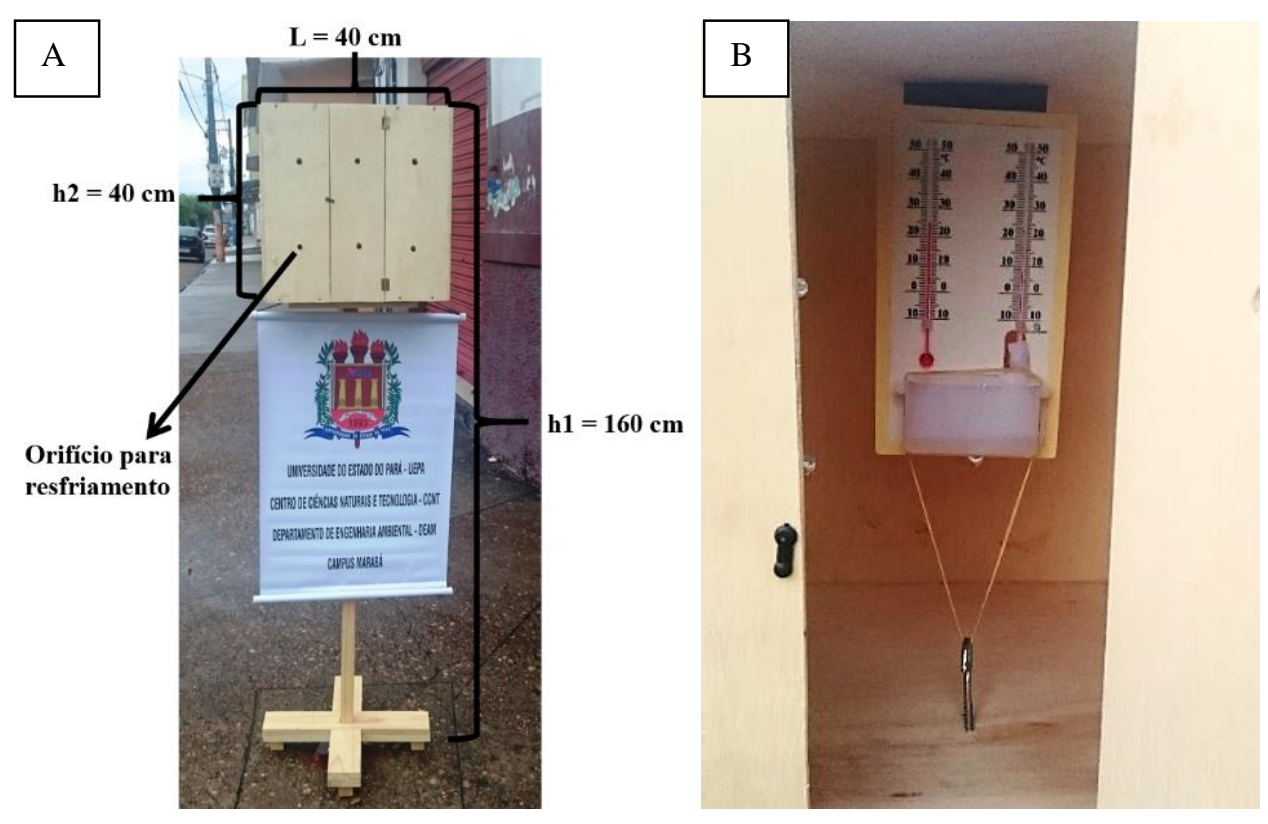

Figura 02 - A) Dimensões do abrigo meteorológico; B) Abrigo meteorológico aberto para visualizar a fixação do termo higrômetro de bulbo seco e bulbo úmido (TBS - TBU).

Figure 02 - A) Dimensions of the weather shelter; B) Weather shelter open to view the attachment of the dry bulb thermoshygrometer and wet bulb (TBS - TBU).

Fonte: Autores (2015).

Métodos e cálculos aplicados

Para a temperatura média do ar atmosférico

Utilizou-se o método preconizado pelo Instituto Agronômico de Campinas (IAC), com duas adequações: (1) quanto à hora (de $07 \mathrm{~h}, 14 \mathrm{~h}$, $21 \mathrm{~h}$, para cada uma hora, durante 12 horas, de $06 \mathrm{~h} 0$ às $17 \mathrm{~h}$ ); (2) em relação à quantidade de leituras, de três, para doze/dias, de segunda a sexta feira, no mesmo intervalo de tempo. Ressalte-se que esse método não indica o número ideal de pontos de leitura. Tais adequações se efetivaram em função da obtenção de maior número de dados possíveis, pois, trata-se de pesquisa exploratória nessa área do município. Quanto ao cálculo da temperatura média horária diurna, utilizou-se a Equação 1 (PEREIRA et al., 2007).

$$
\mathrm{T}_{\text {média }}=\frac{\mathrm{T}_{06 \mathrm{~h}}+\mathrm{T}_{07 \mathrm{~h}}+\mathrm{T}_{08 \mathrm{~h}}+\ldots+\mathrm{T}_{17 \mathrm{~h}}}{12}
$$

Quanto a Diferença Psicrométrica (DP) e Umidade Relativa do ar

Empregou-se o preconizado pelo fabricante (INCOTERM). Os cálculos foram efetuados com as aplicações das Equações 2 e 3.

$$
\begin{aligned}
& D P=T B S-T B U \\
& U R \%=D P \rightarrow T B S
\end{aligned}
$$

Onde:

$\mathrm{T}_{\text {média }}=$ Temperatura média $\left({ }^{\circ} \mathrm{C}\right) ; \mathrm{TBS}=$ Temperatura de Bulbo Seco $\left({ }^{\circ} \mathrm{C}\right)$; TBU $=$ Temperatura de Bulbo Úmido $\left({ }^{\circ} \mathrm{C}\right) ; \mathrm{DP}=$ Diferença Psicométrica $\left({ }^{\circ} \mathrm{C}\right) ; \mathrm{UR} \%=$ Umidade Relativa (\%).

Após a obtenção dos dados nos 23 dias de coleta em doze horas, nos quatro pontos, obtevese um mil cento e quatro medidas para temperatura do ar e umidade relativa do ar, nos dois locais da pesquisa. Os dados foram tabulados, e tratados com o emprego da Estatística descritiva (média, percentagem) e a Correlação de Pearson (para verificar a relação ocorrente essas duas variáveis climáticas), com o uso do software Microsoft Excel (2010). 
Para o conforto térmico

Aplicou-se de setenta formulários mistos (vinte e quatro na área 1, em transito, sob o sol; quarenta e seis na $\mathrm{A} 2$, sob a sombra dos dosséis), durante os dois primeiros dias de coleta, a cada uma hora, durante 12 horas, por dois discentes do curso de Engenharia Ambiental, capacitados para tal. A diferença quanto ao número de formulários aplicados, deve-se às características físicas da A1 (desconforto na área, ou seja, expostas ao sol, e o calçamento estreito), por isso, a maioria das pessoas não estava disposta a responder as perguntas, pois, se parassem para interagirem dificultariam a passagem da população.

Após a coleta desses dados, foram tratados estatisticamente com o uso do Excel (2010), estatística descritiva (frequência absoluta e relativa), em seguida, foi efetuada a classificação de acordo com a tradução da escala de sete pontos (Tabela 02) sugeridas em Predicted Mean Vote (PMV) (ISO 7.730:2005; LYRA, 2007). Tal índice foi aplicado para verificar se os dois ambientes, objetos dessa pesquisa, apresentam as condições de aceitabilidade pela população que frequentam os espaços, em função da presença da arborização.

Tabela 02 - Escala de sensação e preferência térmica elaborada pelo PMV.

Table 02 - Sense of scale and thermal preferably prepared by PMV.

\begin{tabular}{cccc}
\hline Sensação Térmica & \multicolumn{3}{c}{ Preferência Térmica } \\
\hline Muito calor & +3 & Muito mais quente & +3 \\
Calor & +2 & Mais quente & +2 \\
Pouco calor & +1 & Um pouco mais quente & +1 \\
Nem frio, nem calor & 0 & Nem um pouco mais quente & 0 \\
Pouco frio & -1 & Pouco mais frio & -1 \\
Frio & -2 & Mais frio & -2 \\
Muito frio & -3 & Muito mais frio & -3 \\
\hline
\end{tabular}

Fonte: Martini et al (2014).

Sabe-se que, tipos de pavimentações, fenômenos climáticos (Ex.; El Niño), níveis de concretações, barreiras físicas, morfologia urbana, dentre outros, contribuem para a sensação térmica, mas não foram objetos dessa pesquisa.

Em relação ao Índice de Desconforto (ID)

Quanto aos cálculos do ID (Equação 4), empregou-se o índice bioclimático proposto por Thom (1959). Na caracterização dos níveis do desconforto térmico (ID), foi aplicada a classificação preconizada por Giles et al (1990).

$$
I D=0,4(T B S+T B U)+4,8(4)
$$

Após esses cálculos, os resultados foram classificados de acordo com o preconizado por Camargo (2009) (Tabela 03).

Tabela 03 - Faixa de Classificação do Índice de Desconforto de Thom (ID).

Table 03 - Rating range from discomfort Thom index.

\begin{tabular}{ccc}
\hline Faixas & ID $\left({ }^{\circ} \mathbf{C}\right)$ & Nível de desconforto térmico \\
\hline 1 & ID $<15,6$ & Todos se sentem desconfortáveis. \\
2 & $15,6 \leq$ ID $\leq 18,4$ & Aproximadamente $50 \%$ das pessoas se sentem desconfortáveis devido à condição \\
3 & $18,4 \leq$ ID $\leq 23,9$ & seca e fria. \\
4 & $23,9 \leq$ ID $\leq 26,7$ & As pessoas se sentem desconfortáveis \\
5 & $26,7 \geq$ ID & $100 \%$ das pessoas se sentem desconfortáveis devido à alta temperatura e umidade. \\
\hline
\end{tabular}

Fonte: Camargo (2009). 


\section{Resultados e Discussão}

A análise dos resultados para a temperatura do ar e para a umidade relativa indicou uma tendência de valores mais elevados em A1, para temperatura, quando comparada com a A2 (Tabela 04).

Tabela 04 - Médias horárias diurnas, dos 23 dias, da temperatura de bulbo seco e bulbo úmido, e umidade relativa, em A1 e A2.

Table 04 - Daytime average hours, of 23 days, the dry bulb temperature and wet bulb and relative humidity in the areas 1 and 2.

\begin{tabular}{|c|c|c|c|c|c|c|}
\hline \multirow{2}{*}{ Horários } & \multicolumn{3}{|c|}{ A1: Av. Antônio Maia } & \multicolumn{3}{|c|}{ A2: Rua Cinco de Abril } \\
\hline & TBS $\left({ }^{\circ} \mathrm{C}\right)^{1}$ & TBU $\left({ }^{\circ} \mathrm{C}\right)^{2}$ & $\operatorname{UR}(\%)^{3}$ & TBS $\left({ }^{\circ} \mathrm{C}\right)^{1}$ & TBU $\left({ }^{\circ} \mathrm{C}\right)^{2}$ & $\operatorname{UR}(\%)^{3}$ \\
\hline 06h00 & 25,30 & 22,93 & 81,04 & 24,89 & 22,65 & 81,87 \\
\hline $07 \mathrm{~h} 00$ & 26,35 & 23,65 & 79,20 & 25,65 & 23,09 & 80,11 \\
\hline $08 \mathrm{~h} 00$ & 28,02 & 24,78 & 76,04 & 26,65 & 23,74 & 77,72 \\
\hline 09h00 & 30,61 & 26,20 & 70,04 & 28,54 & 24,80 & 73,07 \\
\hline $10 \mathrm{~h} 00$ & 32,67 & 27,26 & 65,13 & 30,39 & 25,70 & 68,24 \\
\hline $11 \mathrm{~h} 00$ & 33,91 & 27,74 & 61,85 & 31,91 & 26,48 & 64,67 \\
\hline $12 \mathrm{~h} 00$ & 35,48 & 28,61 & 59,20 & 33,24 & 27,11 & 61,65 \\
\hline $13 \mathrm{~h} 00$ & 36,63 & 28,96 & 55,57 & 34,11 & 27,41 & 59,37 \\
\hline $14 \mathrm{~h} 00$ & 37,50 & 29,43 & 53,87 & 35,15 & 27,85 & 56,91 \\
\hline $15 \mathrm{~h} 00$ & 38,13 & 29,63 & 52,13 & 36,65 & 28,46 & 53,13 \\
\hline $16 \mathrm{~h} 00$ & 35,83 & 28,15 & 54,80 & 34,93 & 27,54 & 55,80 \\
\hline $17 \mathrm{~h} 00$ & 34,07 & 27,00 & 56,84 & 33,50 & 26,84 & 58,84 \\
\hline Média & 32,88 & 27,03 & 63,81 & 31,30 & 25,97 & 65,95 \\
\hline
\end{tabular}

Onde: ${ }^{1}$ Temperatura de Bulbo Seco; ${ }^{2}$ Temperatura de Bulbo Úmido; ${ }^{3}$ Umidade Relativa. Fonte: Autores, 2015.

Pesquisa efetuada na China, por Huang et al. (2008), indicou que, em áreas onde há bosque urbano e superfície de concreto, as diferenças de temperatura oscilam entre $0,5^{\circ} \mathrm{C}$ a $3,5^{\circ} \mathrm{C}$. A2, em Marabá, apresenta tais aspectos e, as diferenças de temperatura entre as áreas, apresentou valor mínimo igual a $0,47^{\circ} \mathrm{C}$, e máximo igual a $2,52^{\circ} \mathrm{C}$.

Outra pesquisa realizada em Goiás, por Weirich et al. (2015), os autores concluíram que as condições microambientais como (...) temperatura e umidade relativa do ar (...) tendem a variar mais em um ambiente com menos árvores. Em A1 (Av. Antônio Maia), em Marabá, a pouca arborização presente no canteiro central, contribuiu para a tendência de valores elevados quanto a temperatura do ar. Isso corrobora com os resultados encontrados em Goiás.

A análise dos resultados também indicou que às $07 \mathrm{~h}$, a diferença $\left(0,70^{\circ} \mathrm{C}\right)$ na mensuração da temperatura entre A1 e A2, foi o segundo menor valor. Entre 09h a $13 \mathrm{~h}$, as diferenças indicaram tendências de elevação (Tabela 05). Isso ocorreu devido ao ângulo de elevação da incidência solar e à cobertura vegetal ocorrente nas duas áreas pesquisadas.

Em um estudo realizado em Rondonópolis MT, por Silveira e Pereira (2011), os resultados indicaram que ocorreu uma diminuição da temperatura $\left(-2^{\circ} \mathrm{C}\right)$ às $07 \mathrm{~h}$ minutos, em área com maior índice de arborização, quando comparada à área não arborizada. A pesquisa realizada em Marabá, a A1, apresenta arborização escassa e esparsa, com predomínio do oiti (Licania tormentosa), além do início do aquecimento celular nos vegetais, unidades arquitetônicas com recuo frontal, de um piso, gemelares, além de baixo fluxo e contra fluxo, no momento da mensuração (07h). Em função da arborização, na A2, a vegetação é mais densa e espessa (Figura 03A e 03B). 
Tabela 05 - Diferenças médias de Temperatura de Bulbo Seco durante 12h, entre as A1 e A2.

Table 05 - Means differences dry bulb temperature for 12 between A1 and A2.

\begin{tabular}{cccc|}
\hline Horário & $\mathbf{A 1}\left({ }^{\circ} \mathbf{C}\right)$ & $\mathbf{A 2}\left({ }^{\circ} \mathbf{C}\right)$ & $\mathbf{A 1}-\mathbf{A 2}\left({ }^{\circ} \mathbf{C}\right)$ \\
\hline $06 h 00$ & 25,30 & 24,89 & 0,41 \\
$07 h 00$ & 26,35 & 25,65 & 0,70 \\
$08 h 00$ & 28,02 & 26,65 & 1,37 \\
\hline $\mathbf{0 9 h} 00$ & $\mathbf{3 0 , 6 1}$ & $\mathbf{2 8 , 5 4}$ & $\mathbf{2 , 0 7}$ \\
$\mathbf{1 0 h 0 0}$ & $\mathbf{3 2 , 6 7}$ & $\mathbf{3 0 , 3 9}$ & $\mathbf{2 , 2 8}$ \\
$\mathbf{1 1 h} 00$ & $\mathbf{3 3 , 9 1}$ & $\mathbf{3 1 , 9 1}$ & $\mathbf{2 , 0 0}$ \\
$\mathbf{1 2 h} 00$ & $\mathbf{3 5 , 4 8}$ & $\mathbf{3 3 , 2 4}$ & $\mathbf{2 , 2 4}$ \\
$\mathbf{1 3 h} 00$ & $\mathbf{3 6 , 6 3}$ & $\mathbf{3 4 , 1 1}$ & $\mathbf{2 , 5 2}$ \\
\hline $14 h 00$ & 37,50 & 35,15 & 2,35 \\
15 h00 & 38,13 & 36,65 & 1,48 \\
$16 h 00$ & 35,83 & 34,93 & 0,89 \\
$17 h 00$ & 34,07 & 33,50 & 0,57 \\
Média & 32,88 & 31,30 & 1,57 \\
\hline
\end{tabular}

Fonte: Autores, 2015.
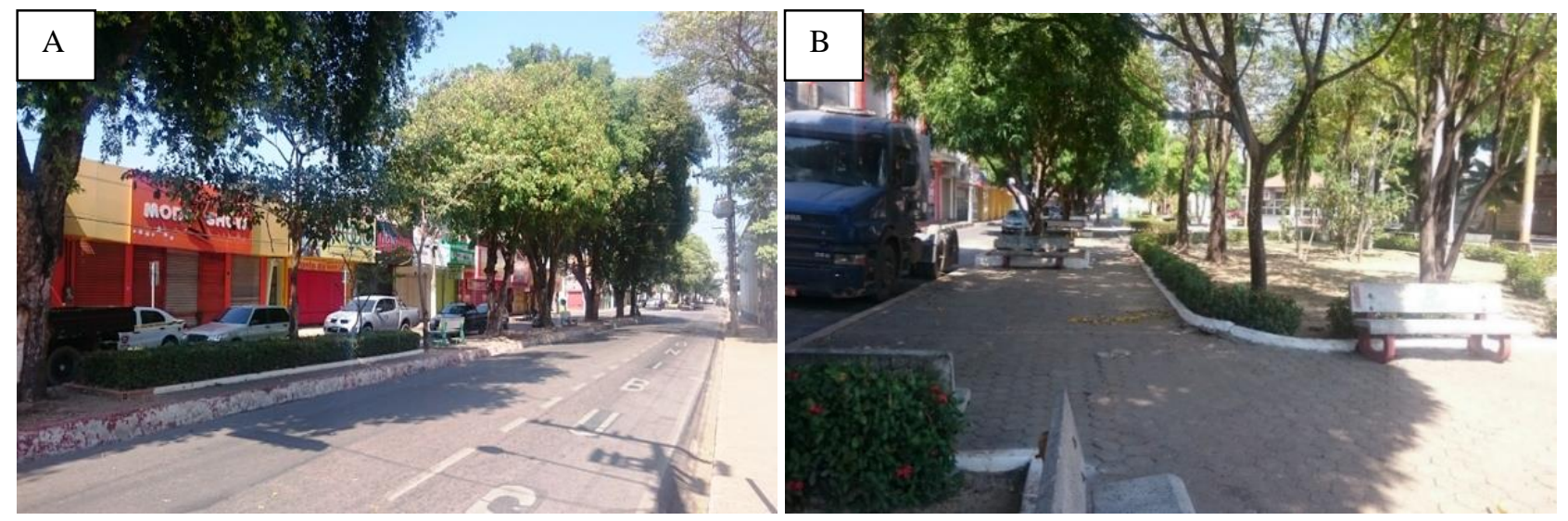

Figura 03 - A): A1 - incidência solar elevada e espaço mal aproveitado para cobertura vegetal. Núcleo Marabá Pioneira. Marabá - Pará; B) Sombreamento proporcionado pela vegetação na A2. Núcleo Marabá Pioneira. Marabá - Pará.

Figure 03 - A) A1 - Amount of sunlight and space barely tapped into canopy tree; B) Shade provided by vegetation in the area 1. Núcleo Marabá Pioneira. Marabá - Pará.

Fonte: Autores, 2015.

Pesquisa realizada em São Paulo - SP, por Shinzato (2009), concluiu que as árvores absorvem em média de 60 a $90 \%$ da energia solar total, (sendo que os outros $10 \%$ é absorvido por rios, entre outros) que pode variar de acordo com a densidade e tipo de folha. Uma árvore densa chega a absorver de 75 - 80\% da radiação solar, e refletir de 15 - 20\%. Em Marabá, a maior densidade da vegetação, com predominância de mangueiras (Mangifera spp L.), oitis (Licania tormentosa), arbustivos, além de plantas rasteiras em canteiros centrais, localiza-se em
A2, com isso, a tendência de menor energia solar. Além disso, esta área está mais próxima do Rio Tocantins (201 m). Outro fator que justifica a variação de temperatura entre as duas áreas analisadas se deve ao teor de umidade contida no ar atmosférico, cujas médias são mais elevadas em A2, quando comparadas com A1.

Em estudo realizado em Torres - RS, por Giralt (2006), o autor concluiu que, em locais com alta umidade, a transmissão da radiação solar é reduzida, porque o vapor de água e as nuvens a absorvem, e a redistribuem na 
atmosfera, refletindo uma parte de volta para o espaço.

Outro estudo, efetuado na Região da Ribeira, em Natal, por Araújo e Caran (2006), indicou que médias elevadas de umidade relativa do ar têm tendências a comportamentos inversamente proporcionais a temperatura, todavia, a proximidade com corpos hídricos tendem a influenciar na umidade relativa do ar, embora ocorra desvios dessas massas pela presença de unidades arquitetônicas verticais e horizontais.

Em Marabá, A2 está a 201,67 m da margem esquerda do Rio Tocantins, e a densidade arbórea, com dosséis espessos, mostra tendências a retenção de umidade, o que contribui para a redução da energia solar, e consequentemente, da temperatura. Então, A2 pode receber influência dessa localização, mas, não tão efetiva, devido as unidades arquitetônicas ali soerguidas.

Quanto à análise dos resultados para umidade relativa do ar, os índices revelaram tendência de valores elevados em A2, com variações mínimas iguais a 0,83\%, e máximas, iguais a 3,80\%, quando comparada com a área 1. Esses resultados também indicaram que, quando a temperatura do atmosférico apresenta tendência de elevação, provoca diminuição na umidade do ar $(\mathrm{r}=-0.98)$. (Figura 04).

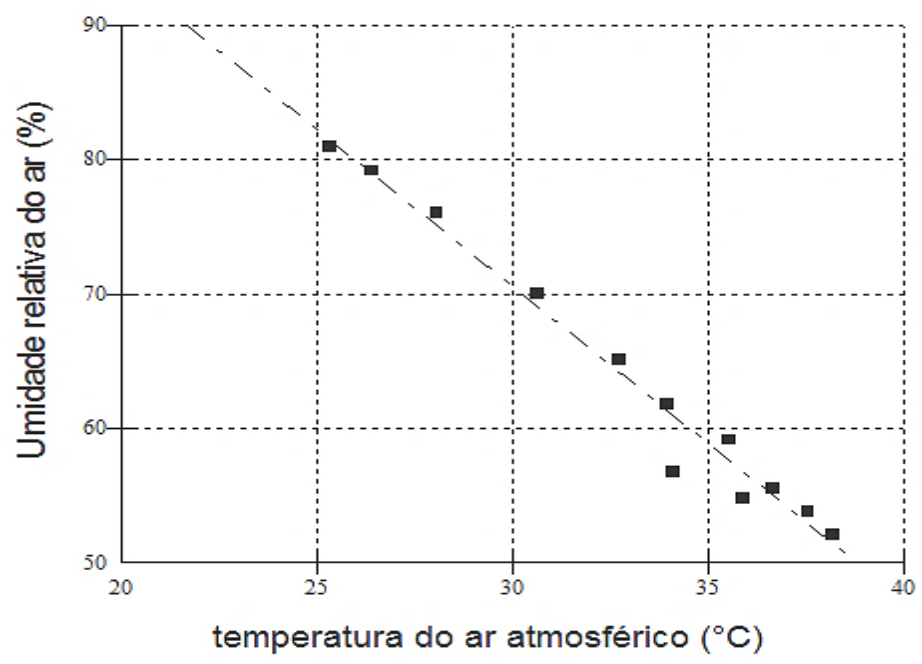

PA.

Figura 04 - Relação entre a tendência de elevação da temperatura e diminuição da umidade do ar atmosférico, nas áreas 1 e 2. Marabá - PA.

Figure 04 - Relation between the tendency of temperature rise and decrease of atmospheric air humidity, in areas 1 and 2. Marabá - PA.

Fonte: Autores (2016).

Em um estudo realizado em Cuiabá - MT, por Franco (2010), o autor concluiu que a umidade relativa (UR) apresentou médias mais elevadas em função das mensurações de temperatura e, em dias em que a UR apresentou médias menores, as médias de temperatura foram mais elevadas. Outro estudo, realizado em Teresina PI, por Kallas (2008), indicou que a relação entre a temperatura do ar e umidade relativa do ar segue a ordem: quanto maior a temperatura do ar, menor a umidade relativa do ar, e, consequentemente, quanto menor a temperatura do ar, maior é a umidade relativa do ar. Em Marabá, nas duas áreas pesquisadas, a análise dos resultados obtidos indicaram uma tendência à similaridade com os estudos realizados em 
Cuiabá e Teresina.

Quanto à sensação térmica, os resultados indicaram que, nas duas áreas analisadas, os indivíduos amostrados "sentem muito calor", ou "calor", independentemente da presença ou ausência de arborização, sombreamento ou não. Após a obtenção dos valores, foi efetuada a classificação preconização na escala de sete pontos do PMV (Tabela 06).

Tabela 06 - Análise da sensação térmica com o uso do Predicted Mean Vote (PMV).

Table 06 - Analysis of thermal sensation using the Predicted Mean Vote (PMV).

\begin{tabular}{cccccc}
\hline \multirow{2}{*}{ Sensação Térmica } & \multirow{2}{*}{ PMV } & \multicolumn{3}{c}{ A1 } & \multicolumn{2}{c}{ A2 } \\
\cline { 3 - 6 } & & $f i$ & $f r^{l}(\%)$ & $f i$ & $f r^{l}(\%)$ \\
\hline Muito calor & +3 & 19,00 & 76,16 & 34,00 & 73,91 \\
Calor & +2 & 5,00 & 20,84 & 12,00 & 26,09 \\
Neutra & 0 & 0,00 & 0,00 & 0,00 & 0,00 \\
Frio & -2 & 0,00 & 0,00 & 0,00 & 0,00 \\
Muito frio & -3 & 0,00 & 0,00 & 0,00 & 0,00 \\
Total & - & 24,00 & 100,00 & 46,00 & 100,00 \\
\hline
\end{tabular}

Onde: ${ }^{1}$ Frequência relativa. Fonte: Autores (2015)

A análise do resultado indicou que $100 \%$ dos indivíduos amostrados, não apresentaram uma percepção ambiental quanto ao calor em função da vegetação arbórea em locais públicos, como ocorre na área 2, pois, relataram que "sentem muito calor" $(73,91 \%)$, bem como na área 1 $(76,16 \%)$, o que resulta em uma diferença mínima $(1,25 \%)$. Porém, há diferença quanto ao número de indivíduos amostrados $(\mathrm{A} 1=24 ; \mathrm{A} 2=$ 46) nas áreas da pesquisa, o que contribuiu para tal proximidade entre os resultados nas duas áreas pesquisadas. Além disso, a análise do ambiente térmico é subjetiva, cada indivíduo o interpreta de forma diferente influenciado por fatores psicológicos e fisiológicos.

Pesquisa realizada em Palmas - TO, por Gonçalves (2009), indicou que a sensação térmica não é influenciada pela umidade relativa nas temperaturas inferiores a $22{ }^{\circ} \mathrm{C}$, mas tornase desagradável quanto maior for a temperatura. Em Marabá, a análise dos resultados indicou, nas duas áreas estudadas, os valores para mínima, de $24^{\circ} \mathrm{C}$ e, para máxima, de $36^{\circ} \mathrm{C}$, o que corrobora com os resultados obtidos em Palmas.

Para o grau de satisfação dos indivíduos amostrados em função do sombreamento, a análise dos resultados indicou um grau classificado como "regular" (média $=41,48 \%$ ), em ambas as áreas analisadas. Porém, não houve classificação para "ruim" para A2, o que foi evidenciado para A1. Outra indicação surpreendente foi quanto à classificação para “ótima”, mais elevada para A1 (Tabela 07).

Tabela 07 - Grau de satisfação quanto á presença de árvores para sombreamento.

Table 07 - How satisfied are the presence of trees for shading.

\begin{tabular}{ccccc}
\hline \multirow{2}{*}{ Presença de árvores quanto ao sombreamento } & \multicolumn{2}{c}{$\mathbf{A 1}$} & \multicolumn{2}{c}{$\mathbf{A 2}$} \\
\cline { 2 - 5 } & $f i$ & $f r^{l}(\%)$ & $f i$ & $f r^{l}(\%)$ \\
\hline Ótima & 5,00 & 20,83 & 4,00 & 8,70 \\
Boa & 7,00 & 29,17 & 23,00 & 50,00 \\
Regular & 10,00 & 41,67 & 19,00 & 41,30 \\
Ruim & 2,00 & 8,33 & 0,00 & 0,00 \\
Total & 24,00 & 100,00 & 46,00 & 100,00 \\
\hline
\end{tabular}

Onde: ${ }^{1}$ Frequência relativa. Fonte: Autores, 2015. 
Estudo efetuado em Uberlândia - MG, por Crosara (2013), indicou que a comunidade sabe da necessidade de uma sombra $(27 \%)$ provocada por arborização em áreas urbanas. Em Marabá, as análises dos resultados indicaram que a satisfação dos indivíduos amostrados se situa entre Boa $(A 1=29,17 \%$; $A 2=50 \%)$ e regular
(A1 = 41,67\%; A2 = 42,30\%). Isso indica que há necessidade de melhorias no processo de arborização em Marabá.

Em relação ao conforto térmico, os resultados obtidos e analisados indicaram que a percepção ambiental dos indivíduos amostrados não está muito confortável com essa variável (Tabela 08).

Tabela 08 - Conforto térmico nas áreas de estudo. Núcleo Marabá Pioneira. Marabá - Pará.

Table 08 - Thermal comfort in the study areas. Núcleo Marabá Pioneira. Marabá - Pará.

\begin{tabular}{ccccc}
\hline \multirow{2}{*}{ Conforto Térmico nas Áreas } & \multicolumn{3}{c}{$\mathbf{A 1}$} & \multicolumn{2}{c}{$\mathbf{A 2}$} & $f r^{l}(\%)$ \\
\cline { 2 - 5 } & $f i$ & $f r^{l}(\%)$ & 0,00 & 0,00 \\
Muito confortável & 0,00 & 0,00 & 4,00 & 8,70 \\
Confortável & 2,00 & 8,33 & 27,00 & $\mathbf{5 8 , 7 0}$ \\
Desconfortável & 3,00 & $\mathbf{1 2 , 5 0}$ & 15,00 & $\mathbf{3 2 , 6 0}$ \\
Muito desconfortável & 19,00 & $\mathbf{7 9 , 1 7}$ & 46,00 & 100,00 \\
Total & 24,00 & 100,00 & &
\end{tabular}

Onde: ${ }^{1}$ Frequência relativa. Fonte: Autores, 2015.

A análise dos resultados indicou que, de acordo com os indivíduos amostrados, há uma tendência de inversão em função da percepção ambiental: A1, desconfortável (12,50\%) e muito desconfortável $(79,17 \%)$; A2, desconfortável $(58,70 \%)$ e muito desconfortável $(32,60 \%)$.

Pesquisa realizada em Brasília - DF, por Godoy et al. (2009), indicou que a relação entre a vegetação e a temperatura de superfície nos parques urbanos dessa cidade na medida que a temperatura aumenta o índice de vegetação fotossinteticamente ativa diminui, por isso, a autora afirma que a vegetação urbana é um fator de manutenção do conforto térmico. Em A2, temos a maior densidade vegetal quando comparada com área A1, isso tende a melhorar o conforto térmico, como foi indicado em Brasília.

Quanto ao índice de Desconforto (ID), os resultados analisados indicaram que ambas as áreas pesquisadas se mostraram desconfortáveis $\left(\mathrm{A} 1=28,76^{\circ} \mathrm{C} ; \mathrm{A} 2=27,70^{\circ} \mathrm{C}\right)$. Tal afirmativa foi efetuada a partir do cálculo efetuado e da análise dos valores obtidos:

$$
\begin{aligned}
& \text { ID }_{\text {A1 }}=0,4(32,88+27,03)+4,8=\mathbf{2 8 , 7 6}{ }^{\circ} \mathbf{C} \\
& \text { ID }_{\text {A } 2}=0,4(31,30+25,97)+4,8=\mathbf{2 7 , 7 0}{ }^{\circ} \mathbf{C}
\end{aligned}
$$

$\mathrm{Na}$ escala, o valor obtido, supera a faixa 5 $\left(26,7^{\circ} \mathrm{C}\right)$. Essa faixa indica que $100 \%$ das pessoas estão insatisfeitas com a temperatura e a umidade relativa do ar. Pesquisa realizada em Curitiba - PR, por Martini (2013), indicou que a percepção ambiental consiste na consciência das sensações advindas da interação entre o homem e o espaço e ocorre de maneira individualizada, visto que depende das experiências anteriores relacionadas às informações sensoriais, culturais e outras armazenadas na memória. Portanto, a percepção do microclima possui variação de acordo com as experiências climáticas vivenciadas pelo indivíduo e ocorre comparando-se o presente ao passado e a outros espaços.

\section{Conclusão}

As tendências para temperatura e umidade relativa do ar nas duas áreas pesquisadas são opostas, quando uma eleva a outra diminui. A arborização em A2 não é suficiente para mitigar a sensação térmica e melhorar a sensação termo higrométrica da população, ou seja, tanto a 
sensação quanto o conforto térmico. Isso indica a necessidade de melhorias na arborização em áreas para que o índice de desconforto, quanto a estas duas variáveis ambientais, diminua e proporcione melhor qualidade ambiental ao Marabaense.

\section{Referências Bibliográficas}

ARAÚJO, B. C. D.; CARAN, R. análise ambiental: estudo bioclimático urbano em centro histórico. Ambiente \& Sociedade, 9, n. 1, p. 149 - 167, 2006.

BARBIRATO, G. M.; SOUZA, L. C. L.; CARN, C. Clima e cidade: a abordagem climática como subsídio para estudos urbanos. Maceió (Al): EDUFAL, 2007.

BORGES, M. G. E. Influência do ambiente construído no microclima urbano. Estudo de caso no Campus da Universidade Federal de Santa Catarina. 2009. 154 f. Dissertação (Mestrado em Arquitetura e Urbanismo). Universidade Federal de Santa Catarina. 2009.

CAMARGO, J. R. Resfriamento Evaporativo - Climatização Ecológica. Rio de Janeiro: Ciência Moderna Ltda., 2009

CROSARA, R. A percepção da população do bairro Jardim Umuarama sobre a importância da arborização. Geosaberes, Fortaleza, v. 4, n. 7. P. 16 - 32, jan/jul, 2013.

CRUZ, G. C. F. Clima urbano de Ponta Grossa - PR: uma abordagem da dinâmica climática em cidade média subtropical brasileira. 2009. 368 f. Dissertação (Doutorado em Geografia) - Faculdade de Filosofia, Letras e Ciências Humanas, Universidade de São Paulo, São Paulo, 2009.

FRANCO, F. M. Configuração Urbana e sua Interferência no Microclima Local: Estudo de Caso no Bairro do Porto em Cuiabá-MT. 2010. 185 f. Dissertação (Mestrado em Física
Ambiental). Universidade Federal do Mato Grosso - UFMT, Cuiabá, 2010.

GARTLAND, L. Ilhas de calor: como mitigar as zonas de calor em áreas urbanas. São Paulo: Oficina de Textos, 2010.

GIRALT, R. P. Conforto térmico em espaços públicos abertos na cidade de Torres - RS. 2006. 238 f. Dissertação (Mestrado em Planejamento Urbano Regional) - Universidade Federal do Rio Grande do Sul, Porto alegre, 2006.

GODOY, L. B.; BAPTISTA, G. M. M.; ALMEIDA, T. Relação entre a vegetação e temperatura de superfície nos parques urbanos do Distrito Federal, por meio de dados ASTER. In: XVI Simpósio Brasileiro de Sensoriamento Remoto.16., 2009. Natal. Anais...Natal: RN, 2009, p. 699 - 705.

GOMES, A. D. Relações entre preferências térmicas humanas no interior de edificações e as temperaturas externas: um estudo sobre o método adotado na norma AHSRAE 55-2004. 2007. 198 f. Dissertação (Mestrado em Construção Civil). Universidade Federal de São Carlos. São Carlos, 2007.

GONÇALVES, C. E. C. Ruas confortáveis, ruas com vida: Proposição de diretrizes de desenho urbano bioclimático para vias públicas. Av. Juscelino Kubitscheck, Palmas TO. 2009. 149 f. Dissertação (Mestrado em Arquitetura e Urbanismo). Universidade de Brasília, Brasília, 2009.

GOOGLE EARTH. Programa Google Earth. Versão 1.3.28.15. 2015. Disponível em: < https://www.google.com/earth/explore/products /> Acesso em: 20 out. 2015.

GYLES, B. D.; BALAFOUTIS, C. H.; MATHERAS, P. Too hot for confort: the heatwaves in Greece in 1987 and 1988. Int. J. Biomet. USA, v. 34, n. 2, p. 98 - 104, 1990.

HUANG, L et al. A fieldwork study on the 
diurnal changes of urban microclimate in four types of ground cover and urban heat island of Nanjing, China. Building and Environment, v.43, p. 7-17, 2008.

ISO. Internacional Organization for Stardardization. Moderate thermal environments - determination of the PMV and PDD indices and specification of the conditions for thermal comfort, ISO 7730. Genebra, 2005.

KALLAS, L. M. E. Desenhando com o clima e a vegetação: Um estudo de caso do loteamento HBB em Teresina - PI. 2008. 167 f. Dissertação (Mestrado em Arquitetura e Urbanismo). Universidade de Brasília, Brasília, 2008.

KÁNTOR, N., et al. Objective and subjective aspects of an urban square's human comfort case study Szeged (Hungary). In: JAPANESEGERMAN MEETING ON URBAN CLIMATOLOGY, 5. 2008, p. 241-246. Albert Ludwig: University of Freiburg, 2008.

LONDE, P. R.; MENDES, P. C. A Influência das Áreas Verdes na Qualidade de Vida Urbana. Uberlândia (MG): Hygeia, Uberlândia, v.10, n.18, p. 264 - 272, 2014.

LOBODA, C. R.; DE ANGELIS, B. L. D. Áreas Verdes Públicas Urbanas: Conceitos, Usos e Funções. Ambiência. Guarapuava, PR, v.1, n.1, p. 125-139, jan./jun, 2005.

LYRA, D. S. F. M. Aplicabilidade de índices de conforto térmico: um estudo de caso em Salvador - BA. 2007. 119 f. Dissertação (Mestrado em Engenharia Ambiental Urbana) Escola Politécnica, Universidade Federal da Bahia, Salvador, 2007.

MARTINI, A. Microclima e conforto térmico proporcionado pelas árvores de rua na cidade de Curitiba - PR. 2013. 129 f. Dissertação (Mestrado em Engenharia Florestal). Universidade Federal do Paraná, Curitiba, 2013.
MARTINI, A. et al. Percepção da população sobre o conforto térmico proporcionado pela arborização de ruas de Curitiba-PR. Curitiba (PR): FLORESTA, Curitiba, v. 44, n. 3, p. 515 - 524, 2014.

MASCARÓ, L; MASCARÓ, J. Ambiência Urbana - Urban Environment. 3 ed. Porto Alegre (RS): +4 Editora, 2009.

MENDONÇA, F.; DANNI-OLIVEIRA, I. M. Climatologia: noções básicas e climas do Brasil. São Paulo: Oficina de Textos, 2007.

MONTEIRO, L. M. Modelos Preditivos de Conforto Térmico: Quantificação de Relações entre Variáveis Microclimáticas e de Sensação Térmica para Avaliação e Projeto de Espaços Abertos. 2008. 378 p. Tese (Doutorado em Tecnologia da Arquitetura). Universidade de São Paulo, São Paulo, 378 p. 2008

MCPHERSON, E.G. Cooling urban heat islands with sustainable landscapes". In: The ecological city: preserving and restoring urban biodiversity, Amherst: University of Massachusetts Press, pp. 151-171.1994.

OLIVEIRA, A. S. influência da vegetação urbana no microclima e uso de praças públicas. 2011. 162 f. Tese (Doutorado em Física Ambiental). Universidade Federal do Mato Grosso. UFMT, 2011.

PEREIRA, A. R.; ANGELOCCI, L. R.; SENTELHAS, P. C. Meteorologia agrícola. Universidade de São Paulo. Escola Superior de Agricultura "Luiz de Queiroz". Departamento de Ciências Exatas. 2007.

PILLAR, V. D. Clima e vegetação. Porto Alegre (RS): UFRGS, 2007.

RORIZ, M. Conforto e desempenho térmico de edificações. São Carlos, 2008. (Apostila). Disponível em: $<$ http://w3.ufsm.br/geese/seqe/wp- 
content/uploads/2010/11/Apostila.pdf>. Acesso em: 23 abr. 2015.

SHINZATO, P. O impacto da vegetação nos microclimas urbanos. 2009. 173 f. Dissertação (Mestrado em Arquitetura e Urbanismo) Universidade de São Paulo, São Paulo, 2009.

SILVEIRA, M. H. D.; PEREIRA, L. R. Influência da arborização urbana no microclima de duas áreas na região central de Rondonópolis - MT. Goiânia (GO): Enciclopédia Biosfera, Goiânia, v.7, n.13, p. 1158 - 1165, 2011.

SOUZA, D. M. Clima urbano no planejamento do município de Ourinhos - SP. 2013. 177 f. Dissertação (Mestrado em Geografia) - Universidade Estadual de Campinas, Campinas.2013.

THOM, E.C. The discomfort index. Weatherwise, Boston, v.12, n.1, p.57 - 60, 1959.

VARGAS, K. E. et al., 2008, Tropical community tree guide: benefits, costs, and strategic planning. Gen. Tech. Rep. PSW-GTR216. Albany, CA: U.S. Department of Agriculture, Forest Service, Pacific Southwest Research Station, 2008.

WEIRICH, R. A. et al. Arborização urbana para mitigação das condições microclimáticas em Goiânia, Goiás. Ecologia e Nutrição Florestal, Santa Maria, v. 3, n. 2, p. 48 - 58, 2015. 